\title{
Foaming of Polylactide in the Presence of Chain Extender
}

\author{
Joanna Ludwiczak $\cdot$ Marek Kozlowski
}

Published online: 25 June 2014

(C) The Author(s) 2014. This article is published with open access at Springerlink.com

\begin{abstract}
An experimental study on the influence of chain extender (CE) on the properties and foamability of two grades of polylactide (PLA) has been carried out. The influence of $\mathrm{CE}$ on the polymer crystallinity and viscoelastic properties that are critical during the foaming process was investigated. After addition of CE an increase in the viscosity and the cold crystallization temperature of PLA was observed. Selection of PLA grade has been correlated with a structure of the polymer. The cellular structure of PLA was obtained during extrusion process using the chemical blowing agent. The addition of 1.0 and $1.5 \%$ CE caused fine cellular structure and low density $\left(0.7 \mathrm{~g} / \mathrm{dm}^{3}\right)$ of foamed PLA.
\end{abstract}

Keywords Foaming - Poly(lactic acid) Chain extender

\section{Introduction}

Microcellular materials are gaining increasing attention due to their low density and a lower consumption of raw materials compared to solid counterparts, good thermal insulating and damping properties. Because of these properties, they are used as lightweight automotive parts, aircraft components, sport equipment, in the construction industry, food packaging [1] and medical applications, including polymer scaffolds [2]. Foamed polymers are produced using the chemical (CBA) or physical blowing agents (PBA) that provide a gas, which must be dissolved in a polymer, then after decompression it forms

J. Ludwiczak $(\bowtie) \cdot$ M. Kozlowski

Faculty of Environmental Engineering, Wroclaw University of Technology, Wybrzeze Wyspianskiego 27, 50-370 Wrocław, Poland

e-mail: joanna.ludwiczak@pwr.wroc.pl nuclei in the polymer matrix which eventually grow into cells [3]. The foaming process allows obtaining a microcellular structure, characterized by a cell size in the range of $0.1-10 \mu \mathrm{m}$ and cell densities in the range of $10^{9}-10^{15} \mathrm{~cm}^{-3}$ [4]. Replacement of traditional materials by biodegradable polymers, as well as reducing material costs due to lower weight of final products is an important goal of many research institutes and industry, looking for the cost savings and more sustainable company profile. A reasonable way to solve the problems associated with the plastics waste, high crude oil prices and a gradual exhaustion of fossil resources seems to be the use of polymers derived from renewable resources. Currently the most popular bio-based polymer is poly (lactic acid) (PLA) synthesized from L- and D-lactic acid [5]. PLA can be also manufactured by the ring-opening polymerization of lactide $[6,7]$. Its biodegradability is a major advantage while implementing in the packaging industry. Various properties of PLA, particularly its degree of crystallinity, the melting point, mechanical, rheological and barrier properties, can be controlled by varying the ratio of stereoisomers of $\mathrm{L}$ - and D-lactic acid $[8,9]$. Despite all the advantages of PLA, there are nevertheless some drawbacks, especially a low molecular weight, which affects the polymer melt viscosity, melt elasticity, mechanical and thermal properties $[10,11]$. One of the possible methods to increase the molecular weight is the use of chain extenders (CE) that cause a change from the linear to long chain branched structures [12]. Chain extension relays on reaction of functional groups of amines, anhydrides, carboxylic acids and isocyanates with the carboxyl or hydroxyl end groups of PLA chains. Zhang et al. [13] have shown that mechanical and thermal properties of TPS/PLA blends were improved by CE addition. An interest in PLA foaming has been noted recently. Matuana et al. [11] performed a foaming extrusion process of poly (lactic acid) with a chemical blowing agent (CBA). Uniform and fine cellular structure can be 
formed in PLA using extrusion process at a suitable combination of the melt flow rate of a polymer, CBA content and processing speed. Density reduction (for about $39 \%$ ) and an increase of the thermal expansion coefficient was achieved by generating a cellular structure in PLA [1]. An improvement of mechanical properties such as the impact strength (four-fold increase) and elongation at break (two-fold increase) for foamed PLA in comparison to the solid matrix was observed. Richards and others [14] were obtained cell sizes in the range of 20-1,500 $\mu \mathrm{m}$ and 3-14 $\mu \mathrm{m}$ for PLA and 75/25 PLA/PHBV blend using batch process. The problem of dimensional stability of pores in amorphous polylactide (PLA) was noted by Lee et al. [15]. They concluded that the increase in crystallinity can be a way to overcome the problems of dimensional stability, provided that it can omit the processing difficulties associated with crystalline polymers. Larsen and Neldin [16] have studied qualitative differences between PLA 2002D, $3251 \mathrm{D}$ and $8052 \mathrm{D}$ at foaming. It was shown that the material density decreased abruptly or gradually as a function of the blowing agent $\left(\mathrm{CO}_{2}\right)$ solubility. It was also noted that in PLA 3251D, despite its low melt viscosity, the cellular structure can be successfully produced in a sufficiently low temperature. Pilla et al. [10] studied the effect of chain extender CESAextend (CE) and talc on the structure of PLA. Addition of talc caused a reduction in the cell size and increased cell density in PLA. Furthermore, after addition of both talc and CE a more uniform cell structure was obtained.

The objective of this paper is to investigate the effect of CE on the foamability of PLA during the microcellular extrusion. The variation of the $\mathrm{CE}$ content and processing parameters on the cell morphology, material density, degree of crystallinity, mechanical, thermal and insulating properties of foamed PLA was investigated.

\section{Experimental}

\section{Materials}

Two grades of PLA (3052D, 2003D) supplied by NatureWorks were used. The CE was Joncryl 4368 (BASF). The general chemical formula for this styrenic-glycidyl acrylate copolymer is given in Fig. 1. PLA was dried at $70{ }^{\circ} \mathrm{C}$ for $4 \mathrm{~h}$ before processing. CBA Hydrocerol CF (Clariant) was used in amount of $0.75 \mathrm{wt} \%$.

\section{Chain Extension}

The chain extension was performed during extrusion using the twin screw extruder CTW100 (Haake) at $165^{\circ} \mathrm{C}$, $45 \mathrm{rpm}$. The CE was added in four contents $(0.2 ; 0.5 ; 1.0$; $1.5 \mathrm{wt} \%)$.

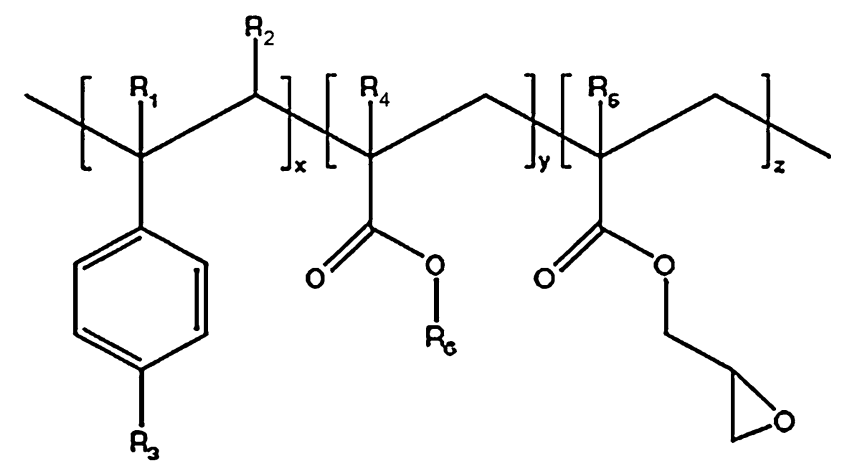

Fig. 1 Joncryl 4368 formula [8]

\section{Crystallinity}

Structural changes in PLA caused by CE have been studied with the differential scanning calorimetry using an instrument DSC Q20 (TA Instruments). A thermal ramp was from -20 up to $250{ }^{\circ} \mathrm{C}$ at the rate of $10{ }^{\circ} \mathrm{C} / \mathrm{min}$ under nitrogen. The percentage of crystallinity was calculated according to:

$$
\begin{aligned}
& \text { Percentage of crystallinity }[\%] \\
& \quad=[\Delta H m-\Delta H c] / \Delta H m^{\circ} \times 100 \%
\end{aligned}
$$

where $\Delta \mathrm{Hm}(\mathrm{J} / \mathrm{g})$ is the melting enthalpy, $\Delta \mathrm{Hc}(\mathrm{J} / \mathrm{g})$ is the cold crystallization enthalpy and $\Delta \mathrm{Hm}^{\circ}$ is the melting enthalpy of a $100 \%$ crystalline PLA reported to be equal to $93 \mathrm{~J} / \mathrm{g}[16]$.

\section{Melt Rheology}

Rheological measurements were carried out with Haake RheoStress 6,000 rotational rheometer (Thermo Scientific) with a plate-plate measuring system and a gap between the plates of $1 \mathrm{~mm}$. The test temperature was $160^{\circ} \mathrm{C}$. The elongational flow of the molten polymer strand was determined using Rheotens apparatus (Göttfert).

\section{Oxygen Permeability}

Estimation of the oxygen permeation rate of thin films (ca. $100 \mu \mathrm{m}$ thick) was performed using MultiPerm analyzer (Extra Solution).

\section{Foaming Process}

Cellular structure was developed during extrusion using the single screw extruder Rheomex 252 (Haake) with 3 barrel zones and the extrusion die. The temperature profile was 150-160-165-145 ${ }^{\circ} \mathrm{C}$. The screw rotation was $15 \mathrm{rpm}$. 
Table 1 DSC results

\begin{tabular}{|c|c|c|c|c|}
\hline Sample & $\begin{array}{l}\mathrm{T}_{\mathrm{g}} \\
\left({ }^{\circ} \mathrm{C}\right)\end{array}$ & $\begin{array}{l}\text { Cold } \\
\text { crystallization } \\
\left({ }^{\circ} \mathrm{C}\right)\end{array}$ & $\begin{array}{l}\mathrm{T}_{\mathrm{m}} \\
\left({ }^{\circ} \mathrm{C}\right)\end{array}$ & $\begin{array}{l}\text { Percentage } \\
\text { of } \\
\text { crystallinity } \\
(\%)\end{array}$ \\
\hline PLA 3052D & 62.3 & 118.8 & 150.1 & 32.7 \\
\hline $\begin{array}{l}\text { PLA 3052D + } 0.2 \% \\
\text { CE }\end{array}$ & 61.4 & 126.3 & 151.1 & 24.7 \\
\hline $\begin{array}{l}\text { PLA 3052D + } 0.5 \% \\
\text { CE }\end{array}$ & 62.6 & 126.4 & 151.6 & 16.5 \\
\hline $\begin{array}{l}\text { PLA 3052D + } 1.0 \% \\
\text { CE }\end{array}$ & 62.7 & 127.1 & 150.9 & 11.9 \\
\hline $\begin{array}{l}\text { PLA 3052D + } 1.5 \% \\
\text { CE }\end{array}$ & 63.2 & 130.7 & 152.0 & 5.1 \\
\hline PLA 2003D & 62.3 & 116.0 & 150.1 & 33.4 \\
\hline $\begin{array}{l}\text { PLA 2003D + } 0.2 \% \\
\text { CE }\end{array}$ & 62.3 & 119.4 & 151.4 & 32.7 \\
\hline $\begin{array}{l}\text { PLA 2003D + } 0.5 \% \\
\text { CE }\end{array}$ & 62.6 & 120.5 & 151.5 & 26.6 \\
\hline $\begin{array}{l}\text { PLA } 2003 \mathrm{D}+1.0 \% \\
\text { CE }\end{array}$ & 63.4 & 128.0 & 152.8 & 12.5 \\
\hline $\begin{array}{l}\text { PLA 2003D + } 1.5 \% \\
\text { CE }\end{array}$ & 63.2 & 128.7 & 153.0 & 11.7 \\
\hline
\end{tabular}

Cellular Morphology

Scanning electron microscopy (SEM) was used to characterize the cellular morphology of foamed samples. Sputtering with gold was performed prior to SEM observations which were carried out with VEGA TESCAN microscope.

Density

The foam density was evaluated by a buoyancy method with the density kit mounted on a balance (Mettler Toledo).

\section{Thermal Insulating Properties}

Thermal conductivity was determined by means of the apparatus Thasys THA01 (Hukseflux Thermal Sensors) using glycerol as a medium in the measuring chamber.

\section{Results and Discussion}

\section{Thermal Properties}

Poly (lactic acid) (PLA) 3052D and 2003D exhibit a semicrystalline structure (the degree of crystallinity of about $33 \%$ ), have a similar glass transition temperature $\left(\mathrm{T}_{\mathrm{g}}\right)\left(62^{\circ} \mathrm{C}\right)$, melting temperature $\left(\mathrm{T}_{\mathrm{m}}\right)\left(150{ }^{\circ} \mathrm{C}\right)$ and cold crystallization temperature $\left(116-118^{\circ} \mathrm{C}\right)$. There was no effect of the $\mathrm{CE}$ on the glass transition and melting temperature of both PLA grades. With an increasing content of

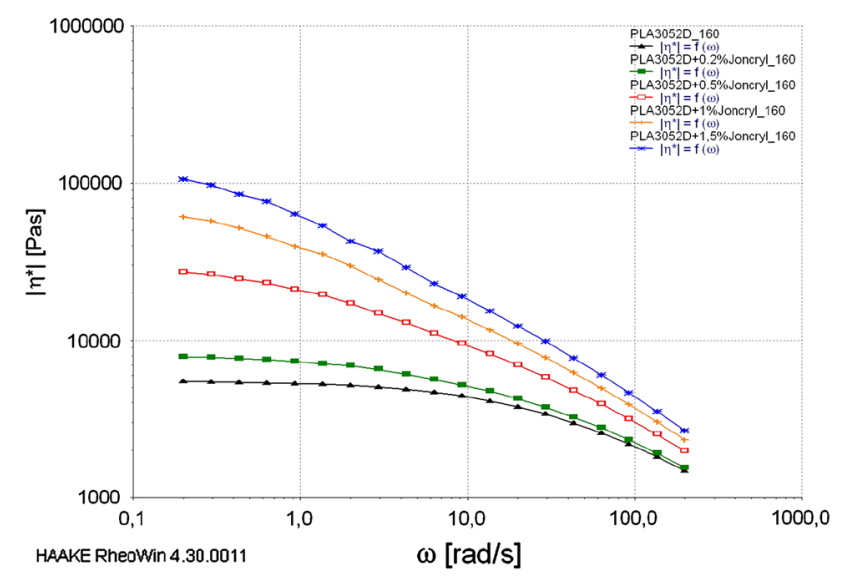

Fig. 2 Viscosity curves of PLA 3052D and PLA + CE

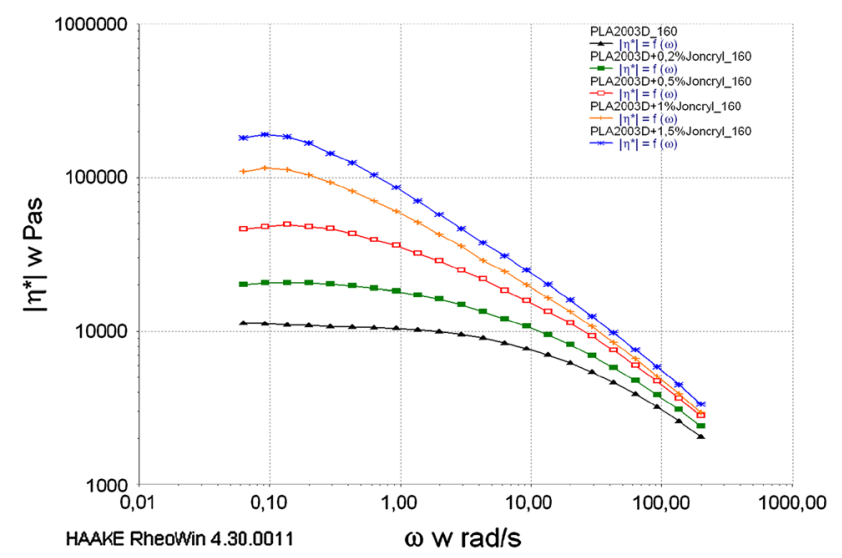

Fig. 3 Viscosity curves of PLA 2003D and PLA + CE

the $\mathrm{CE}$ an increase in the cold crystallization temperature and decrease in the degree of crystallinity of PLA samples was observed (Table 1). The epoxy groups of Joncryl can react with the carboxyl and hydroxyl groups in the polyester, which brings about formation of branched polymer chains. That makes difficult a dense packing of polymer chains, which resulted in a decrease of crystallinity. Reduced mobility of polymer chains due to an increase in the molecular weight, enhanced the temperature of cold crystallization, which is consistent with the literature data. Higher drop in the crystallinity degree that has been observed for PLA 3052D may be related to a difference in the chain length of the two polymers, as evidenced by the difference in viscosity of tested materials (Figs. 2, 3). Shorter chains of PLA 3052D are more easily bound in long chains due to reaction with the $\mathrm{CE}$.

\section{Rheological Properties}

Rheological properties play an important role during the foaming process of polymers. Low melt viscosity and 
Fig. 4 PLA melt strength with accelerated elongation

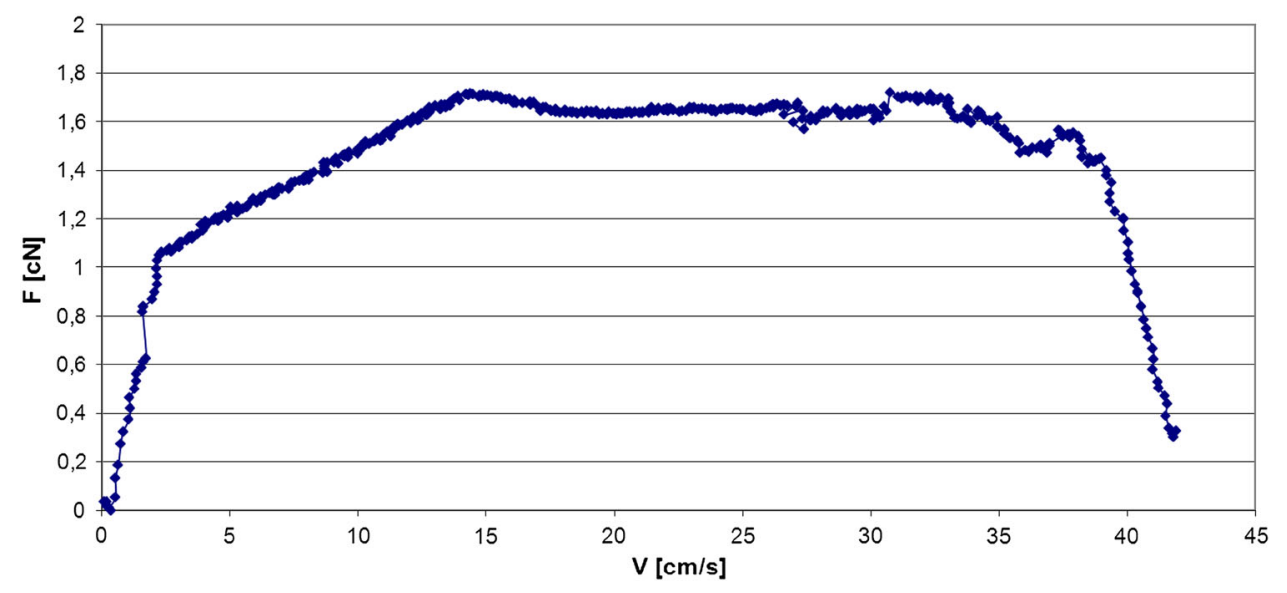

Table 2 Melt strength of PLA and PLA with CE

\begin{tabular}{lc}
\hline Sample & F (cN) \\
\hline PLA 3052D & 1.7 \\
PLA + 0.2 \% CE & 6.9 \\
PLA + 0.5 \% CE & 7.1 \\
PLA + 1.0 \% CE & 9.4 \\
PLA + 1.5 \% CE & 16.7 \\
\hline
\end{tabular}

elasticity allow growing of the pores whereas a high melt strength avoids coalescence of neighboring cells. However, if the melt viscosity is very low, an uncontrolled growth of pores may occur. Rheological studies have shown that both grades of PLA exhibit a pseudoplastic character of flow and PLA 3052D has a lower melt viscosity than PLA 2003D (Figs. 2, 3). Addition of the CE influenced markedly the viscoelastic characteristics of PLA. High increase in viscosity observed for both types of PLA has evidenced that Joncryl is an efficient CE of PLA. PLA 3052D was used in further studies because of its lower viscosity. Results of the elongational flow of molten polymer strands have shown that addition of the $\mathrm{CE}$ brought about an increase in the melt strength confirming a positive impact of the coupling agent on rheological properties. The force that causes a rupture of the polymer strand is $1.7 \mathrm{cN}$ (Fig. 4), whereas addition of $1.5 \%$ of the CE caused 10 fold increase in the melt strength (Table 2).

\section{Oxygen Permeability}

The results presented in Fig. 5 have shown that with an increased content of the CE the oxygen permeability of PLA 3052D became higher. That may be interpreted in terms of a lower crystallinity and higher free volume of the polymer with extended/branched chains.
Cellular Morphology

The structure in PLA 3052D obtained during foaming extrusion has been presented in Fig. 6. The pore size equals to ca. $250 \mu \mathrm{m}$ (Fig. 6a). Addition of the CE caused generation of a large number of small cells. The finest cellular structure (pore size of $20-50 \mu \mathrm{m}$ ) of PLA was observed after addition of 1.0 and $1.5 \%$ of the CE (Fig. 6d, e). The foam morphology can be correlated with the viscoelastic characteristics of the melts.

Neat PLA is a low viscous fluid within which the cells may grow easily to a large diameter. Additionally a low melt strength facilitates merging of neighbouring cells into large pores. In contrary, PLA with addition of the CE exhibited 10-folds higher melt viscosity, therefore the cells growth is more difficult and high melt strength protects the cells of coalescence.

\section{Density}

Density of all foamed materials is lower than that of the solid polymer $\left(1.24 \mathrm{~g} / \mathrm{dm}^{3}\right)$ for about $30-40 \%$ (Fig. 7). Foamed PLA 3052D has a density of $0.8 \mathrm{~g} / \mathrm{dm}^{3}$ due to a high number of large cells. Addition of the CE brought about formation of much smaller pores in PLA matrix. The lowest density $\left(0.7 \mathrm{~g} / \mathrm{dm}^{3}\right)$ has been observed for a polymer modified with $1.5 \%$ of the CE.

\section{Thermal Insulating Properties}

Foaming allowed to reduce the thermal conductivity coefficient of foamed PLA 3052D for about $36 \%$ and about $42 \%$ of foamed PLA with $1.5 \%$ CE compared to a solid polymer (Fig. 8). The results are in a good agreement with the cell morphology - the best thermal insulating properties have been obtained for the foams with a large number of small cells. 
Fig. 5 Oxygen permeability of PLA 3052D and PLA 3052D with $\mathrm{CE}$

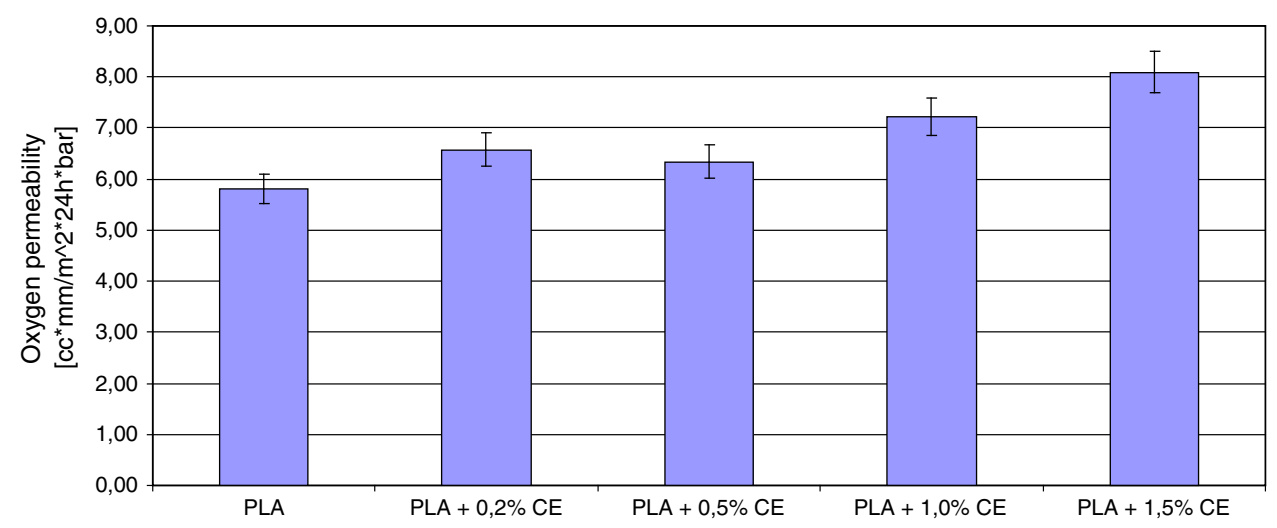

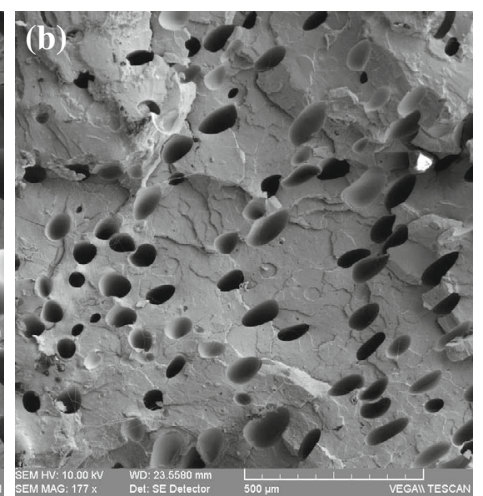
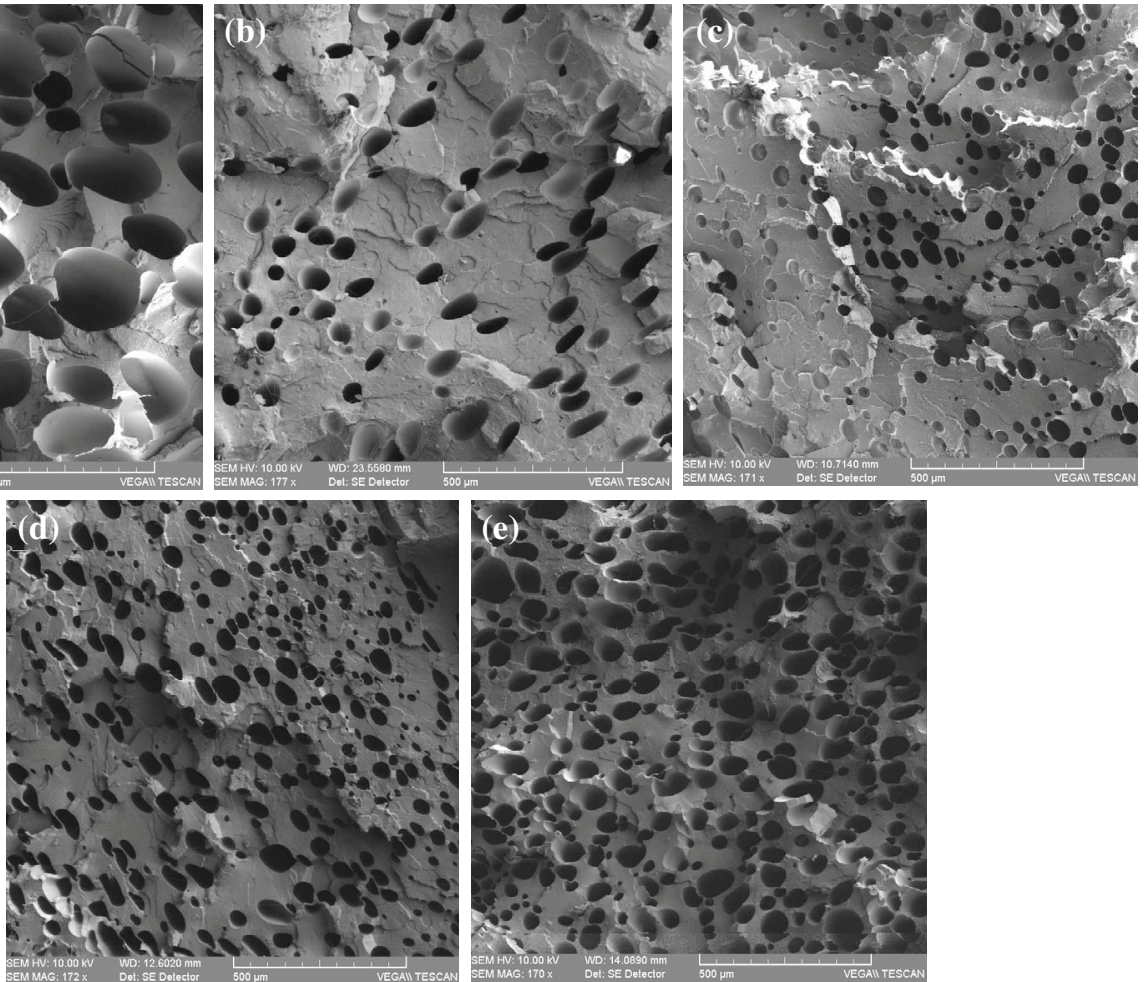

Fig. 6 Cellular structure of foamed polylactide. a PLA, b PLA $+0.2 \%$ CE, c PLA $+0.5 \%$ CE, d PLA $+1.0 \%$ CE, e PLA $+1.5 \%$ CE

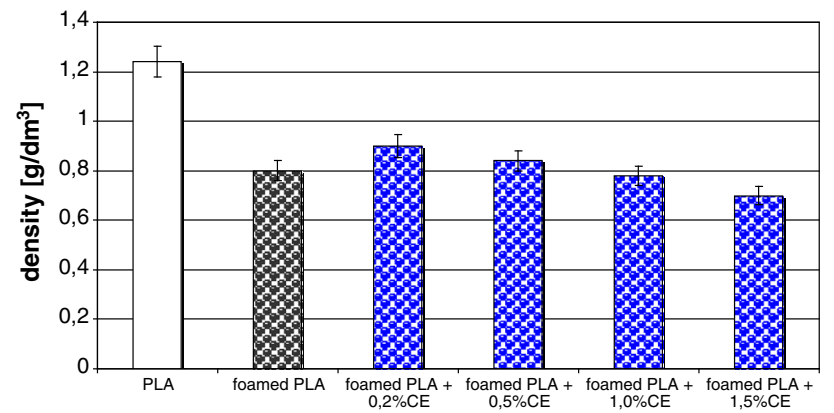

Fig. 7 Density of foamed materials

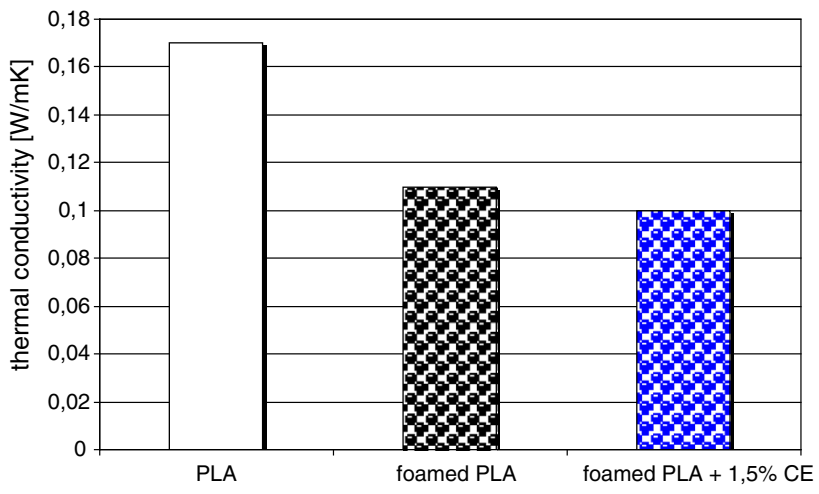

Fig. 8 Coefficient of thermal conductivity 


\section{Conclusion}

The CE has a significant impact on the foamability of PLA during the foaming extrusion. The addition of CE caused an increase in the temperature of cold crystallization, enhanced melt viscosity, reduced degree of crystallinity and barrier properties. The CE influenced markedly the cellular structure of PLA promoting generation of a large number of small cells. The finest cellular structure (pore size of about $20-50 \mu \mathrm{m}$ ) of PLA was observed after addition of 1.0 and $1.5 \% \mathrm{CE}$ agent that resulted in the lowest density $\left(0.7 \mathrm{~g} / \mathrm{dm}^{3}\right)$ and thermal conductivity $(0.1 \mathrm{~W} / \mathrm{mK})$.

Acknowledgments The research was supported by Wroclaw Research Center EIT+ under the project 'The Application of Nanotechnology in Advanced Materials'- NanoMat (POIG.01.01.02-02002/08) financed by the European Regional Development Fund (Innovative Economy Operational Programme 1.1.2). Authors wish to thank Dr. S. Frackowiak for his help in rheological measurements and Dr. M. Gasior for microscopic images.

Open Access This article is distributed under the terms of the Creative Commons Attribution License which permits any use, distribution, and reproduction in any medium, provided the original author(s) and the source are credited.

\section{References}

1. Matuana LM (2008) Bioresour Technol 99:3643

2. Tan Q, Li S, Ren J, Chen C (2011) Int J Mol Sci 890:904

3. Baldwin DF, Park CB, Suh NP (1996) Polym Eng Sci 36:1425

4. Park CB, Behravesh AH, Venter RD (1998) Polym Eng Sci 38:1812

5. Cabedo L, Luis Feijoo J, Pilar Villanueva M, Lagaron JM, Gimenez E (2006) Macromol Symp 233:191

6. Carothers WH, Hill JW (1932) J Am Chem Soc 54:1566

7. Inkinen S, Hakkarainen M, Albertsson A-C, Sodergard A (2011) Biomacromolecules 12:523

8. Gupta B, Revagade N, Hilborn J (2007) Prog Polym Sci 32:455

9. Garlotta D (2002) J Polym Environ 9:63

10. Pilla S, Kim SG, Auer GK, Gong S, Park CB (2009) Polym Eng Sci 49:1653

11. Matuana LM, Faruk O, Diaz CA (2008) Bioresour Technol 23:5947

12. Villalobos M, Awojulu A, Greeley T, Turco G, Deeter G (2006) Energy 31:3227

13. Zhang YY, Yuan X, Liu QQ, Hrymak A (2012) J Polym Environ 20:315

14. Richards E, Rizvi R, Chow A (2008) J Polym Environ 16:258

15. Lee ST, Kareko L, Jun J (2008) J Cell Plast 44:293

16. Larsen A, Neldin C (2013) Polym Eng Sci 53:941 